\title{
Behaviour of Mass Towards Traffic Congestion in Faisalabad City Paksitan
}

Ayesha Saleem

\author{
Lecturer/Coordinator Department of Geography Faculty of science and Technology \\ Government College University Faisalabad, Pakistan. Email: ayeshageographer@gmail.com
}

Khaleeque Kamboh

Lecturer University Community College Faisalabad, Pakistan.

Email: kamboh mkh@yahoo.com

Doi:10.5901/jesr.2014.v4n1p531

\section{Abstract}

Socio-economic development in the cities is well dependent on transport system these days. Causes of traffic congestion and the assessment of public behavior towards traffic congestion are main purposes of the study. Faisalabad city is made representative of the scenario since it is found that every major junction of the city is facing the problem of traffic congestion. For the purpose data was collected from main roads of Faisalabad through primary and secondary sources. It is revealed by the results that most of the respondents thought that heavy traffic, lack of parking space, pedestrian and slow moving traffic.

Key words: Traffic congestion, slow moving traffic, parking space, transport system, traffic management

\section{Introduction}

Every day many people spend hours struck in traffic jams. The problem has many serious physical and mental effects on the dweller of the city and often emergency vehicles are also indulged in the scene. The purpose of this research is to analyze the causes of traffic congestion in Faisalabad city as felt by its residents. Today cities depend on transport system for their socio-economic development. Rising traffic congestion is an inescapable condition in all large and growing metropolitan areas across the world (Qureshi I et al 2007). By the best transport system, a country can be a well-developed and progressive (Ali. Z et al 2012). The major causes of traffic congestion in metropolitan cities are considered the development of new buildings, lack of planning, (Mayer, 1990) lack of law implementation, Rickshaws and unplanned stoppage and different speed vehicles (Khaled Mahmud et al 2012). Faisalabad is fastest growing city in Pakistan. It is the second largest industrial city with an estimated population of 1.6 million in 1994. In early 1980 publically owned buses were introduced but they do not exist today (Faisalabad Divisional Commissioner 1994). have worked on various causes of traffic congestion. There studies emphasizes on the new development, absences of adequate mitigation measures, heavy traffic and slow moving traffic in developed in developing countries of the world. There are many methods introduced by scholars to detect traffic congestion as Zito, R (1999) described that traffic congestion is identified by different kind of detectors, such as loop vehicle detector, ultrasonic radar detector, and microwave detectors and so on. Data was also collected from Jinan traffic police. In developing region, the traffic management system is poor that's why traffic jam due to road network elongate time period. To somewhat lighten this problem he gives solution Local de congestion protocol. He also explain the poor traffic management due to following reasons which are (1)Unplanned city (2)Poor discipline (3)Alternate traffic means(4)Archaic management(5)Tighter budget(VipinJain et al 2012) 


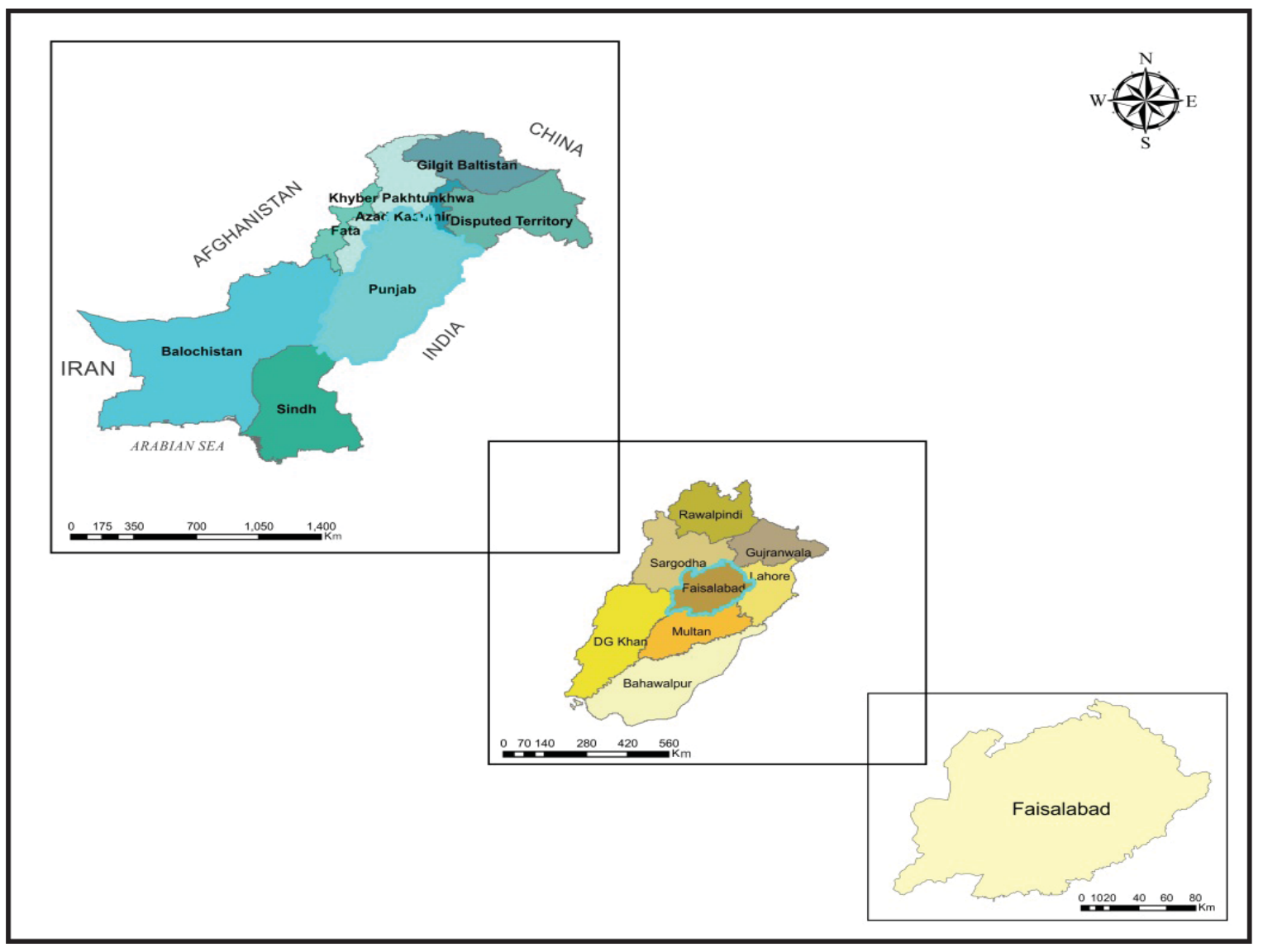

\section{Figure 1 Location of Study area}

The following are the aim of present study:

1. To check the causes of traffic congestion

2. To know the behavior of people towards the traffic congestion

3. To suggest some solution to control traffic congestion

\section{Research Methods}

The present research has been conducted in Faisalabad city (Pakistan). The data was collected using quantitative approach. Two chowks were identified to observe traffic congestion (Gumtee chowk and Chiniot bazaar chowk) after conducting a pilot survey. A sample of 235 respondents was taken and the data was recorded on structured questionnaires through field survey. The data was coded and tabulated in Statistical packages for social sciences. 


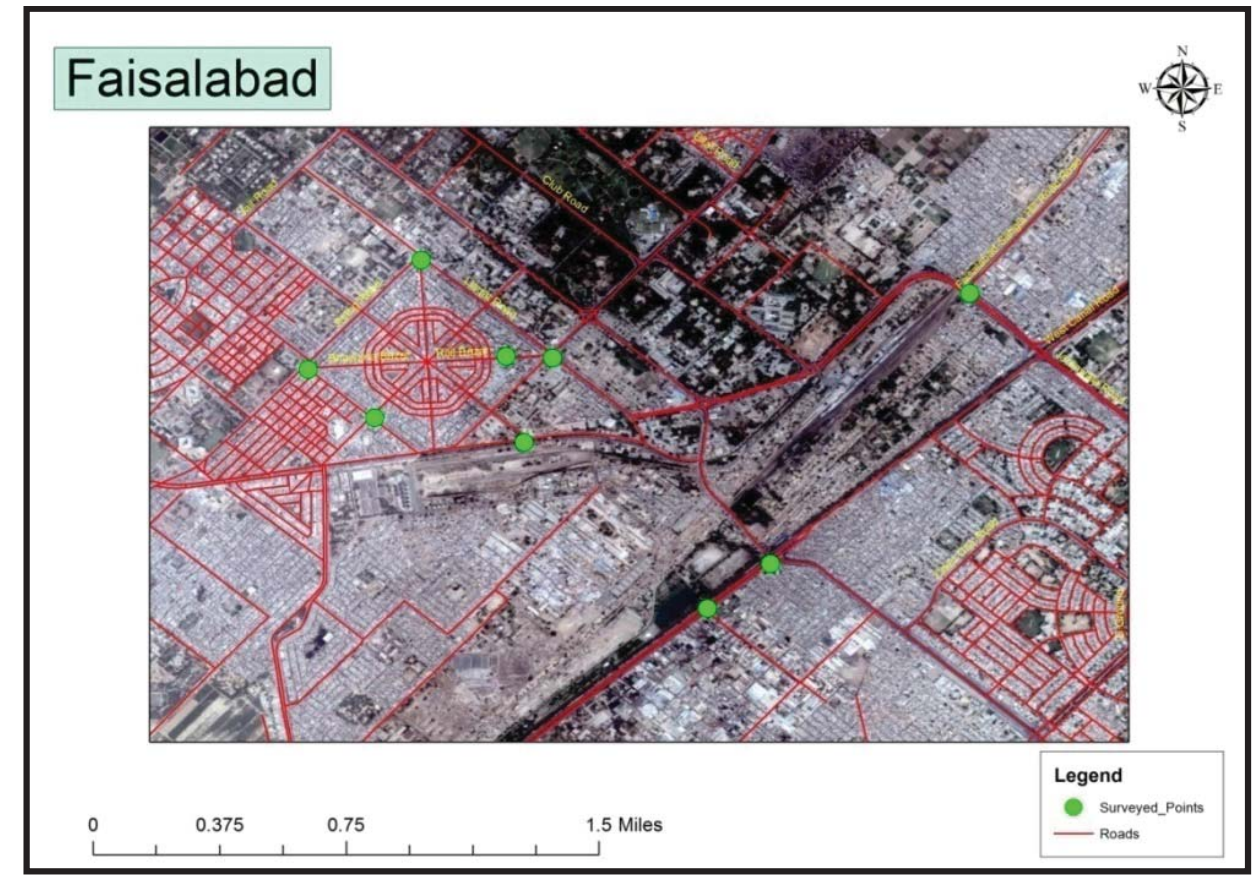

Figure 2 The location of roads in Faisalabad

\section{Analysis and Results}

The following results were quoted by the respondents as the main causes of traffic congestion.

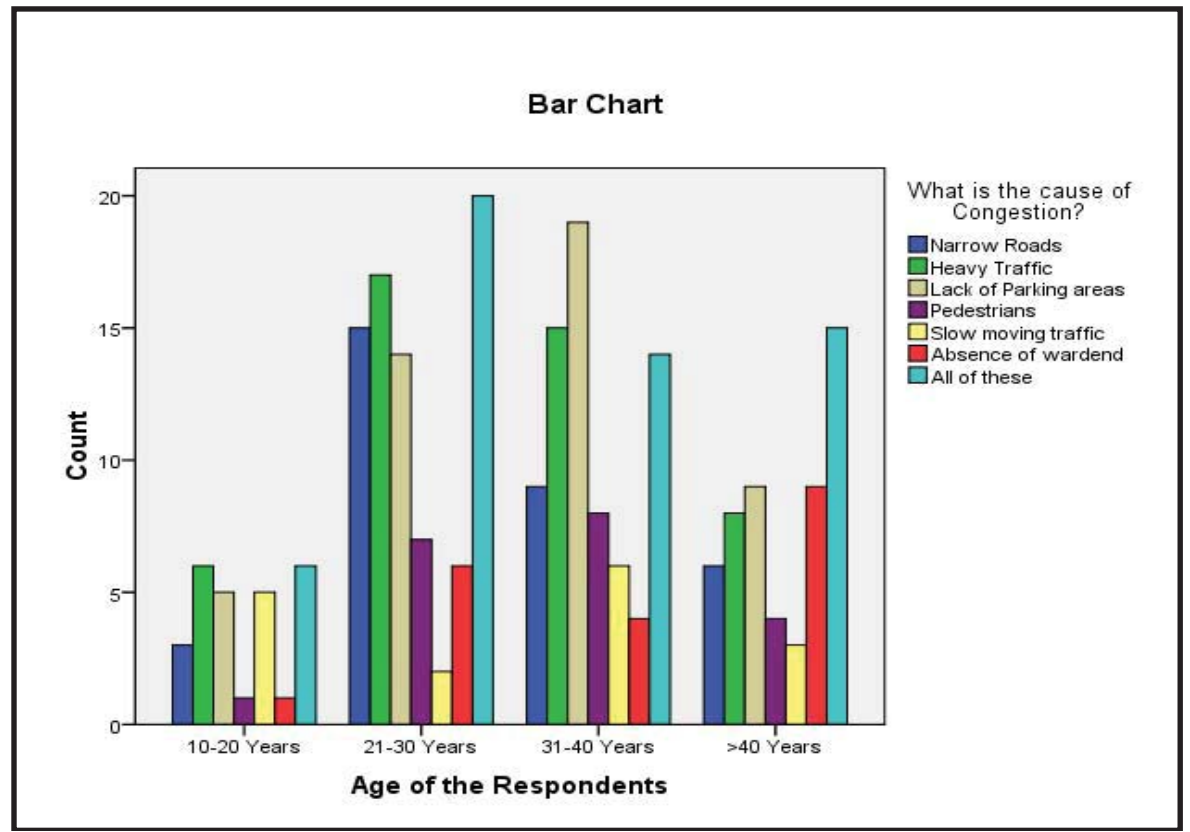

Figure 3 age of the respondents and causes of traffic congestion 
As the figure shows most of the respondents are between the ages 21-30 years; second largest age group of respondents is 31-40 years and third is above than 40 years. According to the respondent of age group 10-20 years, major cause of traffic congestion is heavy traffic and minor cause is pedestrians and absence of wardens. Mostly people consider that all these factors are the causes of traffic congestion. People of this age consider that the lack of parking area and slow moving traffic is the second major causes of traffic congestion whereas narrow roads are the third major cause.

\begin{tabular}{|c|c|c|c|c|}
\hline \multirow[b]{2}{*}{$\begin{array}{l}\text { What is the cause of } \\
\text { Congestion? }\end{array}$} & \multicolumn{3}{|c|}{ Status of the Respondent } & \multirow[b]{2}{*}{ Total } \\
\hline & Vehical Driver & Common Public & Traffic Warden & \\
\hline \multirow{7}{*}{$\begin{array}{l}\text { Narrow Roads } \\
\text { Heavy Traffic } \\
\text { Lack of Parking areas } \\
\text { Pedestrians } \\
\text { Slow moving traffic } \\
\text { Absence of wardens } \\
\text { All of these }\end{array}$} & 20 & 13 & 0 & 33 \\
\hline & 25 & 20 & 1 & 46 \\
\hline & 21 & 26 & 0 & 47 \\
\hline & 12 & 8 & 0 & 20 \\
\hline & 5 & 11 & 0 & 16 \\
\hline & 15 & 5 & 0 & 20 \\
\hline & 28 & 27 & 0 & 55 \\
\hline Total & 126 & 110 & 1 & 237 \\
\hline
\end{tabular}

According to the respondents between age group of 21-30 years, among all these causes of traffic congestion heavy traffic is the major cause, narrow roads is at second and lack of parking area is at the third as suggested by the respondent. According to them pedestrians is the fourth and absence of wardens is fifth cause of traffic congestion. Slow moving traffic is considered as the minor cause by this age group. It is the largest age group of respondents and they also suggested that all causes are collectively responsible for traffic congestion as well. Second largest age group of respondents is 31-40 years, according to them lack of parking area is the major cause of traffic congestion and heavy traffic is considered the second major cause. At third all of these causes collectively are considered responsible for traffic congestion whereas the narrow roads and pedestrians are the fourth and fifth major causes and they consider that the slow moving traffic and absence of wardens are minor reasons. The age group of respondents above 40years of age is the third largest group of respondents. Most of them said that all these are the causes of traffic congestion collectively are actors of the scene. Lack of parking area and absence of wardens are considered second major reason of traffic congestion. Heavy traffic is third major setback according to the respondents of this age group. Some people said that the narrow roads are the difficulty for traffic that is the fourth major factor and at fifth cause according to them are pedestrians. They consider slow moving traffic as a minor cause of traffic congestion. Above tables shows the causes of traffic congestion according to status of the respondents. Majority of vehicle drivers pointed out that narrow roads, lack of parking space, slow moving traffic, heavy traffic and absence of traffic warden are the causes of traffic congestion while common public also highlighted the same reasons mainly but lack of parking as the second most important cause. On the other side traffic wardens only highlighted the heavy traffic at main roads as cause of congestion.

\section{Conclusions}

Traffic congestion has become a serious problem in developed as well as developing countries due to its negative impacts either these are economic, social or cultural (Banik. B, 2009). The situation is worst in Asia especially in south Asian countries. To understand the causes and severity of impacts, most congested, busy roads and junctions of Faisalabad City were selected. Selected areas for studying cause and impact analysis of traffic congestion are GUMTEE CHOWK, JHANG BAZAR CHOWK, KARKHANA BAZAR CHOWK and RAIL BAZAR CHOWK. According to present study, the Faisalabad city is facing the worst situation regarding traffic congestion. It was observed that every junction or confluence point in the study area is facing traffic jam, this situation leads to a number of problems including health problem and making the sites prone to the occurrence of Road Traffic Accident casualties. The study revealed that city is facing a drastic situation regarding traffic congestion. Every major junction of the city is facing the problem of traffic congestion. This situation imprints a question mark on local governing bodies along with traffic controlling authorities. 


\section{Suggestions and recommendations}

According to the study, the Faisalabad city is facing the worst situation regarding traffic congestion. There is need of parking space in Karkhana bazar and Gumtee Chowk (Circular road). Qinigqi rickshaws should not be allowed in Jhang bazar. Public should be obeying traffic rules and regulations. Wardens should be deployed there to control the traffic congestion. All the administrative institutions should work with collaboration of each other. Legislative institutions should form some legislation regarding traffic rules violation and hefty fine.

\section{References}

Ali Z. (2012). Growing Traffic in Peshawar: An Analysis of Causes and Impacts. A Research Journal of South Asian Studies, 27, 409420.

Banik B. (2009). Study of Traffic Congestion in Sylhet city. Journal of the Indian Roads Congress,550, 75-86.

Khaled Mahmud, KhonikaGope and Syed MustafizurRahmanChowdhury (2012) Possible Causes \& Solutions of Traffic Jam and Their Impact on the Economy of Dhaka City. Journal of Management and Sustainability, 2, 112-135.

Kohsaka, H. (2001). Applications of GIS to urban planning and management: Problems facing Japanese local governments, Geo Journal.52, 271-280

Meyer, M.D. (1990). Dealing with congestion from a regional perspective: The case of Massachusetts", Transportation, 16, 197220.

Naila Sharmeen, Kimiaie Sadat, Nishat Zaman, Suman Kumar Mitra. (2012). Developing a Generic Methodology for Traffic Impact Assessment of a Mixed Land Use in Dhaka City. Journal of Bangladesh Institute of Planners,5, 119-128.

Qureshi I A, Huapu L. (2007). Urban Transport and Sustainable Transport Strategies: A Case Study of Karachi, Pakistan", Tsinghua Science and Technology,12, 309-317.

Takyi Harriet, Kofi Poku and Anin Kwabena Emmanuel. 2013. An Assessment of Traffic Congestion and Its Effect on Productivity in Urban Ghana. International Journal of Business and Social Science, 4, 225-234.

Vipin Jain, Ashlesh Sharma and Lakshminarayanan. (2012). Road Traffic Congestion in the Developing World S. America 1-10.

Zito R. (1999). Using GPS to Measure Traffic System Performance".Computer-Aided Civil and Infrastructure Engineering, I 14, 255-265. 
